\section{PAEDIATRIC MORBIDITY FROM CYCLONE NARGIS}

\section{A. Tyebally}

Children's Emergency, KK Women's and Children's Hospital, Singapore, Singapore

Introduction: Cyclone Nargis struck on $2^{\text {nd }}$ May 2008 and was the worst natural disaster in the recorded history of Myanmar. More than 2 million people were affected by the cyclone which left 146 , 000 people dead. Children made up a significant proportion of those affected by the cyclone and they formed a significant patient load during Team Singapore's medical relief mission. It was our aim to study the paediatric morbidity to help in planning for future disaster relief missions.

Methods: Demographic and medical data from the medical records of the 4489 patients seen by our doctors was collected and analysed.

Results: 1402 paediatric patients aged 16 years and below were seen in 9 operational days from our visits to a hospital, 8 camps/villages and an orphanage. They formed more than $30 \%$ of our total clinical workload. Most of them suffered from respiratory $(36 \%)$ and gastrointestinal infections $(29 \%)$. Injuries and wounds made up $12 \%$ of the attendances and $2.8 \%$ of the children presented with psychological manifestations/ post traumatic stress disorder.

Conclusions: Children are more susceptible to infection and vulnerable to the effects of vomiting and diarrhea and often form a large population of victims in a disaster. Their psychological needs have to be addressed. The needs of children are unique and medical aid should be rendered by paediatric specialists trained to render medical assistance to children in extreme situations. The special requirements of children must be taken into account in the planning of any disaster relief mission.

\section{HEAD INJURIES IN CHILDHOOD}

T. Syriopoulou', G. Nikolaou², M. Papoula', E. Karachanidi' ${ }^{1}$, E. Michael ${ }^{1}$, E. Kostopoulou', E. Fourlani ${ }^{3}$, E. Georgiopoulou ${ }^{2}$

${ }^{1}$ Pediatric Department, ${ }^{2}$ Surgical Department, ${ }^{3}$ Associate of Pediatric Department, General Hospital of Kalamata, Kalamata, Greece

Background and aims: We studied during 3 years ( 2007- 2009) 579 children, 1-14 years old ( 402 boys, 177 girls ) who were administrated to Emergency Room of our Hospital because of head injury.

Methods: The study' s children were classified according to sex, age ( 1-4 years old, 5-8 years old, 9-14 years old ), trauma's type, way and place of injury.

Results: In 138 children (23.8\%) were observed injuries of head's soft tissues, in $228(39.4 \%)$ ruptured injuries, in $81(14 \%)$ small injuries and hacks, in 5 $(0.9 \%)$ injuries that caused concussion, in $85(14.6 \%)$ traumatic brain injuries. Accidents were more often happened because of falls, at $83.4 \%$ of children (at home at $29.4 \%$, outdoors at $54.5 \%$ and at school at $16.1 \%$ ), while $7.3 \%$ of incidents concerned car accidents. Increased injuries' frequency was mainly observed at children $1-4$ years old, at $56.1 \%$, boys in majority. 52 children (9\%) were hospitalized for further observation, while $1 \%$ was evacuated.

\section{Conclusions:}

1. The commonest type of injuries are head's ruptured injuries followed by soft tissues' injuries.

\section{Boys are more prone to injuries.}

3. The recorded injuries' sequence is not low although it usually concerns not severe damages. However, is underlined the need of prevention and promotion of measures parents' information and education to avoid similar incidents. 